\title{
Editorial: Ritual Unions
}

\author{
FINTAN WALSH
}

She stands monumentally tall, her hair piled towards the sky, like a lighthouse in a grassy sea. Thomas J. Price's Reaching Out depicts an anonymous black girl staring down at her smartphone, as the currents of accelerated construction, a children's playground and canal-side wildlife crash at her heels for attention (Fig. 1). Frozen in time with bronze, this nine-foot-tall figure is both alone and immersed in a world other than the one we share. Disinterested in her immediate surroundings, she is doing her more important things, interacting with whomever or whatever it is that has caught her eternal attention.

Price's statue was unveiled in London in August 2020, towards the end of a summer of Black Lives Matter protests and debates concerning what to do with the statues of those implicated in racist histories. In the UK, this unrest peaked in June of last year, with the toppling of the statue of slave trader Edward Colston into the river Avon in Bristol, its graffitied carcass eventually salvaged for humiliating horizontal display in the city's M Shed museum a year later.

Unlike statues of famous historical figures, Price's sculpture is not set in a prominent place. Instead, it is tucked away in what is known as the Line, a trail of

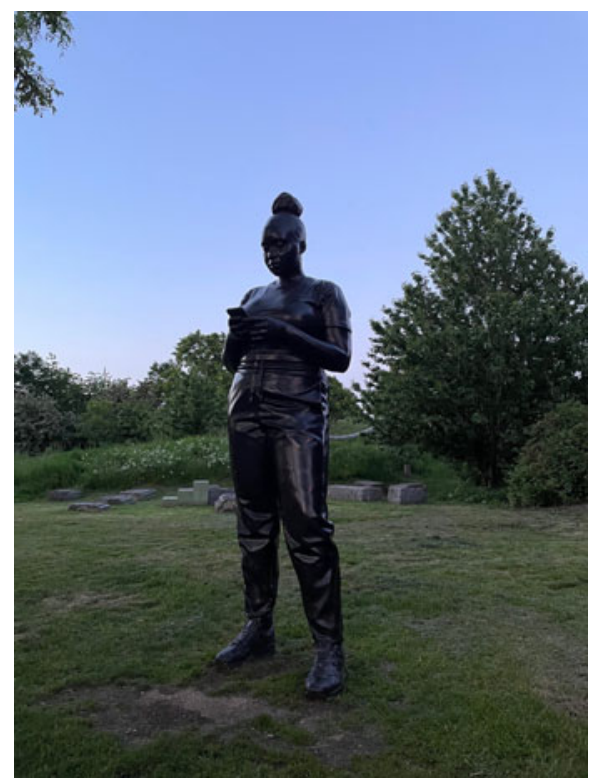

FIG. 1 Thomas J. Price, Reaching Out (2020). Photograph by Fintan Walsh. 
public art running along the edge of East London, from the Elizabeth Olympic Park in Stratford to the $\mathrm{O}_{2}$ in north Greenwich. The Line cuts through a post-industrial belt, much of which has been upturned by post-Olympics' investment and gradually transformed into a sterile strip of newly built apartments. Historically one of the most culturally diverse and poorest parts of London, community life is increasingly hard to discern among the towering blocks of rarely seen residents. 'They call this a city', poet Jay Bernard writes of a London filleted by state-sanctioned neglect; 'I call it the dark between two bodies'.

This is the dark between in which I also live, but it was not until the pandemic struck that I felt compelled to explore my local area in any great depth. I have walked by Price's statue most days this past year, charmed and awed, marvelling at its singular composure as the rest of the world seemed to crumble: a girl just being a girl, a statue just being a statue, a world trying to stay connected as routine social processes halted - gazing at screens, viewing public art, walking, writing, standing up, just being still.

As theatre scholars, makers and audiences, we are in the business of reaching out figuring out how best to do it, how to resist it, gauging its danger and power. Over the course of my tenure as Senior Editor of this journal, these too have been recurring themes, considered across different cultures, forms and historical periods. In my first editorial $(44,1,2019)$, written in the countdown to Brexit, I found myself preoccupied with the closing of borders that seemed set to produce isolationism, reify the nation state, curtail movement and demonize migrants, speculating how theatre and performance might offer alternative avenues of communication and signification. While writing this, my last editorial, it appears as if attempts to erect impassable frontiers have only intensified, apparent everywhere from the resurgence of violence in Israel-Palestine, to the continued deaths of asylum seekers at sea, to the vaccine nationalism that leads wealthy countries to stockpile medical supplies. Despite human efforts to delineate neat boundaries in this way, the natural world does not seem to agree - regions collapse, disease spreads globally, the ocean is on fire, the body of baby Artin Iran-Nejad washes onto a Norwegian shore, the remains of one Kurdish-Iranian family's attempt to reach the UK from France. So often humans say, 'We are this, you are that,' and the rest of the world reminds us of how we are one.

What is the work of theatre and performance in this climate of border control and blasting? How do we bridge the gap between our need to expand and unite and the will to diminish and divide? Against a backdrop of geopolitical and ecological upheaval, we currently find ourselves in a time when the careers of theatre and performance artists have been destroyed in the fallout of COVID-19; when the academic job market is bleak; when performing arts programmes and departments are threatened with closure; and when, as in the UK, the value of an arts and humanities education is systematically undermined by the government, capitalizing on the fallout of the pandemic to fuel corporate ambitions kindled decades ago. During this time of shifting priorities, we are called upon to defend ourselves more forcefully than ever.

I have wondered about these issues during the past three years; asked myself how our disciplines and industries can remain resilient under the weight of such pressure? 
What might an international theatre journal be for beyond the mere publication of articles? How can it serve advocacy as well as research? How might it facilitate forms of exchange not easy to replicate elsewhere? How does a journal stay international while serving more local urgencies? How does a readership foster membership, and how does membership cultivate sustained and engaged citizenship? What are the routes and obstacles to this kind of flourishing?

Like many of us grappling with the same conditions, I have more questions than answers, but find some assurances among the habits of our authors and readers. For instance, I have come to learn that there is an extraordinary enthusiasm for our subject: last year we published articles from approximately thirty different countries, downloaded 53,901 times - an increase of 48 per cent on the previous year. I have realized that in its commitment to publishing research from around the world in each issue, our journal has a unique contribution to make to the ecology of theatre journals, by giving space to undocumented practices and discerning international patterns and echoes where we assumed there were none. I have discovered that in order to live up to our mission, we cannot always wait for writing to find us; instead, we must go looking for it among new scholars, at working groups and at conferences, guiding its development carefully and patiently across cultural conventions, languages and time zones. I have come to believe that part of the editor's job is to trust what authors find interesting about their topic, regardless of our personal preferences, and that part of the responsibility is to help readers also see what is so captivating. I have learned that what is international can feel very local and immediate, when effectively shared between the pages of a journal.

Many of these ideas circled my mind when preparing this issue, which is united by a desire to extend and connect beyond the boundaries of individual bodies, social expectations, geographical contours and spatial parameters. In the writing presented here, we encounter unions, reunions and communions that beam hope towards a post-pandemic horizon. Our opening article discusses Mexico's Caravana de Madres Centroamericanas (Caravan of Central American Mothers), a form of transnational mother-led activism that calls attention to the disappeared in the region, and in some cases leads to family reunification. Ana Elena Puga's 'The Caravana of Central American Mothers in Mexico: Performances of Devotional and Saintly Motherhood on a Transnational Stage-in-Motion' demonstrates how the caravans function as a kind of moving theatrical stage, which challenge the image of mothers as passively suffering, by showing them as active citizens of change where successive governments have failed. Puga argues that these women symbolically unify the countries of Central America, by boldly traversing nation states.

Adam Alston's article also engages with gender-defying images of women in performance, in particular the witchy communism of contemporary feminist practice. In "Burn the Witch": Decadence and the Occult in Contemporary Feminist Performance', Alston explores how decadent thought and occult aesthetics inform the work of the Famous Lauren Barri Holstein and some of her contemporaries, analysing how theatrical conjunctures of the decadent and the occult challenge misogyny and the sanitizing and sanctifying of women, while subverting presumptions of reproduction under capitalism as inherently beneficent. 
Justyna Biernat's article takes us further off-road, to consider how Poland's Węgajty Theatre has cultivated a different kind of communing with nature. In 'The Landscape of Węgajty Theatre', Biernat discusses the evolution of independent and experimental culture in Poland between the 1970s and 1990s, of which Węgajty Theatre formed a part. Established by Erdmute and Wacław Sobaszek in a rural settlement in the 198os, Węgajty Theatre's approach was deeply rooted in the rhythms of rural life as the basis for performance creation and community building. The case of Węgajty Theatre broadens our understanding of the geography of alternative theatrical histories, taking us from the metropolitan centres to the rural margins, and reminds us of the long and complex historical terrain of ecologically sensitive art and community making.

In 'Bulbs Onstage: Theatrical Hygiene and the Electrification of Performance', Ulf Otto leads us back to the electrification of theatres in Germany at the turn of the twentieth century, to examine the relationship between illumination and social organization. In particular, by focusing on the marketing of Edison bulbs and Adolphe Appia's stage designs, Otto analyses the ways in which electrification was understood to bring performers and audiences together in a safer, cleaner and healthier way, and how these ideas took their most sinister turn in the belief that electrical light could support a model of racial hygiene.

With 'Oh, I Know I've Been Changed', Richard Schechner shares his experience of participating in a week of workshops at the Workcenter of Jerzy Grotowski and Thomas Richards in Paris in 2019. His journal excerpts, both off-the-cuff and reflective, are couched in a richness of insight that can only be gleaned from decades of sustained investment in performance practice. The piece recalls an intensity of practice unavailable to most of us since the pandemic began, and reminds us of the unique and sometimes transformative power of working together in shared time and space.

Finally, this issue includes a dossier of shorter articles from scholars and artists working in Brazil. The plan for this contribution was hatched at IFTR Shanghai in 2019, and it has since developed against a backdrop of sociopolitical, medical and ecological upheaval, and the complexities and sensitivities of linguistic and cultural translation. 'Fighting Back: Contemporary Theatre in Brazil' offers readers a vivid glimpse of some of the ways in which the current Bolsonaro administration has harmed women, in particular transgender women and black women, as well as indigenous peoples and the climate. The overall picture is one of life under threat, but in these articles we also have a sense of individuals and collectives fighting back, harnessing theatre's capacity for political representation, active citizenship and community organization.

What I have also learned from editing this journal is that international work is also deeply social, dependent on goodwill and cordial cooperation. My greatest debts are to our wondrous editorial team who have always made this communication possible and pleasurable: Silvija Jestrovic, Tanya Dean, Caoimhe Mader McGuinness, Mary Caulfield, Charlene Rajendran, Cristián Opazo, Marcus Tan and Leah Sidi. Even this past year, while shouldering additional personal and professional pressures, each member has enthusiastically kept this particular show going, and we are all grateful to them for their outstanding dedication. Thanks are ever due to the journal's editorial 
board and peer reviewers, and all at Cambridge University Press who ensure supported and smooth publication. I'm delighted to pass the editorship over to the inimitable hands of Silvija and her incoming editorial team who will ensure that Theatre Research International continues to provide an essential platform for extending conversations between authors and readers around the world, no matter how distant or divided we might sometimes feel.

NOT E

$1 \quad$ Jay Bernard, 'Pride', in Bernard, Surge (London: Chatto \& Windus, 2019), pp. 43-4, here p. 43. 